\title{
ANALYSIS OF FACTORS THAT CAUSE STRESS IN DENTISTS: LITERATURE REVIEW
}

\author{
Syafrudin Aulia Azhar \\ Faculty of Economics, \\ Sultan Agung Islamic University, Jalan Raya Kaligawe, KM 4. Semarang, 50112, Indonesia \\ Email: rudiraulia22@gmail.com \\ Heru Sulistyo \\ Faculty of Economics, \\ Sultan Agung Islamic University, Jalan Raya Kaligawe, KM 4. Semarang, 50112, Indonesia
}

Email: heru@unissula.ac.id

\begin{abstract}
Abstrak: Tenaga kesehatan merupakan suatu pekerjaan dimana seseorang harus mengabdikan diri dalam bidang kesehatan, termasuk profesi dokter gigi. Standar Kompetensi Dokter Gigi menjelaskan bahwa seorang dokter gigi dalam menjalankan tugasnya dituntut untuk bersikap profesional. Dokter gigi diakui sebagai profesi yang penuh tekanan serta merekapun menganggap profesi mereka lebih stres daripada tenaga kesehatan lainnya. Stres dikaitkan dengan penurunan kinerja, dalam profesi terkait kesehatan tentunya akan mempengaruhi pelayanan kesehatan terhadap pasien. Artikel ini bertujuan untuk mengulas faktor-faktor apa yang menjadi pemicu stres kerja pada dokter gigi, sehingga pelayanan terhadap pasien memiliki kualitas dan mutu yang baik. Berdasarkan studi literature didapatkan hasil bahwa factor yang paling sering membuat dokter gigi stress yaitu lingkungan kerja dan konflik dengan rekan kerja, serta faktor faktor lain yang juga berpengaruh yaitu tuntutan kerja, keadaan organisasi, finansial, dan dukungan sosial. Sangat penting bagi dokter gigi untuk bisa mengidentifikasi level stress untuk bisa memberikan pelayanan yang baik dan memberikan performa maksimum dalam berkerja.
\end{abstract}

Kata kunci: Stres; Tenaga Kesehatan; Dokter Gigi.

Absract: Health workers is an occupation in which a person must dedicate himself in the field of health, including the dental profession. Dentist Competency Standards explain that a dentist in carrying out his duties is required to be professional. Dentists are recognized as a stressful profession and they also consider their profession more stressful than other health workers. Stress is associated with decreased performance, in health-related professions will certainly affect health services to patients. This article aims to review what factors trigger work stress at the dentist, so that service to patients has good quality. Based on literature studies, it is found that the factors that most often make a dentist stress are work environment and conflict with coworkers, as well as other factors that also influence work demands, organizational conditions, financial, and social support. It is very important for dentists to be able to identify stress levels to be able to provide good service and provide maximum performance in work.

Keywords: Stress; Health Workers; Dentists.

Article History: Received 2020-03-07; Revised 2020-04-08; Accepted 2020-04-13

\section{PENDAHULUAN}

Dunia Kesehatan saat ini semakin keras dan ketat. Indonesia saat ini sedang berada di era kesehatan baru dengan Menteri Kesehatan yang baru. Kementerian Kesehatan Indonesia memiliki visi "Terwujudnya Masyarakat Sehat, Produktif, Mandiri dan Berkeadilan untuk Menuju Indonesia Maju yang Berdaulat, Mandiri, dan Berkepribadian berlandaskan Gotong Royong". Kementerian Kesehatan bertujuan meningkatkan akses dan mutu pelayanan kesehatan menuju cakupan kesehatan

Syafrudin Aulia Azhar ${ }^{1}$, Heru Sulistyo ${ }^{2}$ - Analysis Of Factors That Cause Stress In Dentists: Literature Review

[Vol 11, No 1 (2020): April 2020] JBTI 
semesta dengan penekanan pada penguatan pelayanan kesehatan dasar (Primary Health Care) dan peningkatan upaya promotif dan preventif didukung oleh inovasi dan pemanfaatan teknologi. Hal tersebut perlu didukung dengan ketersediannya tenaga kesehatan yang professional (Kemenkes 2020).

Berdasarkan UU RI no.36 tahun 2014 tentang Tenaga Kesehatan, tenaga kesehatan merupakan setiap orang yang mengabdikan diri dalam bidang kesehatan serta memiliki pengetahuan dan keterampilan melalui pendidikan di bidang kesehatan yang untuk jenis tertentu memerlukan kewenangan untuk melakukan upaya kesehatan. Tenaga kesehatan dikelompokkan ke dalam tenaga medis termasuk dokter umum dan dokter gigi, tenaga keperawatan, tenaga psikologi klinis, tenaga kebidanan, tenaga kefarmasian, tenaga kesehatan masyarakat, tenaga gizi, dan tenaga kesehatan lain. Tenaga kesehatan memiliki peranan penting untuk meningkatkan kualitas pelayanan kesehatan yang maksimal kepada masyarakat agar masyarakat mampu meningkatkan kesadaran, kemauan, dan kemampuan hidup sehat sehingga mampu mewujudkan derajat kesehatan yang setinggi-tingginya sebagai investasi bagi pembangunan sumber daya manusia yang produktif secara sosial dan ekonomi. Tenaga kesehatan memiliki beberapa petugas yang dalam kerjanya saling berkaitan yaitu dokter, dokter gigi, perawat, bidan, dan ketenagaan medis lainnya (Peraturan Pemerintah No 32 Tahun 1996).

Keputusan Konsil Kedokteran Indonesia nomor 23/KKI/KEP/XI/2006 tentang Standar Kompetensi Dokter Gigi menjelaskan bahwa seorang dokter gigi dalam menjalankan tugasnya dituntut untuk bersikap profesional. Setiap dokter gigi juga wajib menunjukkan kinerja yang prima (bestpractices) pada waktu melakukan pelayanan. Untuk mencapai kompetensi tersebut, pendidikan dokter gigi yang merupakan pendidikan profesi harus didasari oleh keilmuan yang kokoh. Dengan demikian seorang dokter gigi akan mempunyai kompetensi akademik-profesional yang diperoleh melalui pendidikan profesi yang didasari oleh pendidikan akademik, sehingga setelah selesai pendidikannya akan memiliki kemampuan melaksanakan praktik sesuai dengan keahliannya, bersikap profesional, dengan selalu membekali dirinya dengan pengetahuan dan keterampilan yang sesuai dengan perkembangan ilmu pengetahuan dan teknologi. Dokter gigi menjadi salah satu peran yang paling penting dalam kemajuan kesehatan Indonesia. Kinerja dokter gigi sebagai tenaga kesehatan yang berkualitas tidak dapat diperoleh dengan mudah tetapi harus didasari dengan kedisiplinan tinggi dan kerja keras (Sholekhah 2017). Dokter gigi yang memiliki loyalitas yang tinggi akan menjadi aset penting dalam memajukan tempat kerjanya, contoh adalah rumah sakit. Tidak hanya memberikan pelayaan kepada pasien, tentunya dokter gigi tidak terlepas dari banyaknya tekanan dari dalam ataupun luar rumah sakit seperti kondisi tempat kerja yang kurang kondusif, akreditasi rumah sakit, kesejahteraan tempat kerja, bimbingan mahasiswa kedokteran gigi, masalah interpersonal dan sebagainya yang menyebabkan timbulnya stres.

Saat ini stres merupakan masalah umum yang terjadi dalam kehidupan umat manusia (Gaol 2016). World Health Organization (WHO) menyebutkan bahwa sekitar 450 juta orang di dunia mengalami stres. Berdarakan profil kesehatan Indonesia tahun 2008 tercatat sekitar $10 \%$ dari total penduduk Indonesia mengalami stres. Stres didefinisikan sebagai suatu reaksi yang seseorang alami ketika dihadapkan dengan tuntutan dan tekanan yang tidak sesuai dengan kemampuan mereka dan sesuatu yang menantang kemampuan mereka untuk mengatasinya. World Health Organization (WHO) menyebut stres bukan suatu penyakit. Namun, jika stres hebat dan berlangsung selama beberapa waktu, itu dapat menyebabkan kesehatan mental dan fisik (misalnya, depresi, gangguan saraf, penyakit jantung). Stres sering terjadi di tempat kerja. Jika tidak dikelola dengan baik, stres bisa berdampak pada kesehatan dan kesejahteraan seseorang menjadi buruk (Leka, Griffiths and Cox 2004). Stres juga didefinisikan sebagai reaksi yang tidak diharapkan muncul sebagai akibat tingginya tuntutan lingkungan kepada seseorang individu (Wirawan 2012). Stres juga didefinisikan sebagai respon psikologis individu dalam menghadapi suatu kejadian yang mengancam dan mengganggu kemampuan individu tersebut untuk menghadapinya. Adanya tuntutan pada individu

Syafrudin Aulia Azhar ${ }^{1}$, Heru Sulistyo ${ }^{2}$ - Analysis Of Factors That Cause Stress In Dentists: Literature Review

[Vol 11, No 1 (2020): April 2020] JBTI 
yang menekan, menentang, dan membebani atau melebihi daya penyesuaian yang dimiliki individu tersebut akan memicu timbulnya stress (Willda 2016). Stres yang ada saat ini adalah sebuah atribut kehidupan modern. Hal ini dikarenakan stres sudah menjadi bagian hidup yang tidak bisa terelakkan. Baik di lingkungan sekolah, kerja, keluarga, atau dimanapun, stres bisa dialami oleh seseorang. Stres juga bisa menimpa siapapun termasuk anak-anak, remaja, dewasa, atau yang sudah lanjut usia. Dengan kata lain, stres pasti terjadi pada siapapun dan dimanapun. Yang menjadi masalah adalah apabila jumlah stres itu begitu banyak dialami seseorang. Dampaknya adalah stres itu membahayakan kondisi fisik dan mentalnya (Gaol 2016). Jelas bahwa stres yang berlebihan bisa membahayakan setiap orang (Gaol 2016). Banyaknya tugas dan tanggung jawab seorang tenaga kesehatan terutama profesi dokter gigi mengakibatkan terjadinya stres kerja.

Stres kerja merupakan sesuatu kondisi ketegangan yang menciptakan adanya ketidakseimbangan fisik dan psikis yang mempengaruhi emosi, proses berpikir, dan kondisi seorang karyawan. Stres ini merupakan tuntutan untuk dapat menyesuaikan diri dengan tuntutantuntutan yang berlangsung. Tuntutan bisa merupakan kejadian saat ini (faktual) dan bisa juga halhal yang mungkin terjadi di masa yang akan datang, tetapi dipersepsi secara faktual. Stressor adalah tuntutan-tuntutan untuk menyesuaikan diri. Stres memiliki ciri identik dengan perilaku beradaptasi dengan lingkungan, termasuk hal di luar diri (outer world) dan dalam diri (inner world). Orang dikatakan adapatif jika mampu menyesuaikan dengan tuntutan orang lain dan juga memenuhi kebutuhan diri (Wiramihardja 2015). World Health Organization (WHO) menyatakan stres merupakan epidemi yang menyebar ke seluruh dunia. The American Institute of Stress menyatakan bahwa penyakit-penyakit yang berhubungan dengan stres telah menyebabkan kerugian ekonomi Amerika Serikat lebih dari $\$ 100$ miliar per tahun. Survey atas pekerja tenaga perawat pelaksana di Amerika Serikat menemukan bahwa 46\% merasakan pekerjaan mereka penuh dengan stres dan 34\% berpikir serius untuk keluar dari pekerjaan mereka 12 bulan sebelumnya karena stres ditempat kerja (Fajrillah 2016)

Situasi yang dipandang stressful (menekan) dilihat berdasarkan kejadian traumatis, kejadian yang mereka sebabkan, atau tidak dapat dikontrol, tidak terprediksi, atau suatu perubahan besar dalam hidup, dan konflik internal. Kontrol terhadap suatu kejadian menentukan kejadian dipersepsi menekan atau tidak. Semakin tidak terkontrol situasi, semakin dilihat stressful. Kejadian yang dapat diprediksi dapat menurunkan keparahan dari stres. Perubahan dalam hidup yang membutuhkan beberapa penyesuaian dapat dinilai sebagai hal yang menekan. stres juga dapat berasal dari dalam diri karena konflik internal, yaitu isu yang tidak terselesaikan baik sadar maupun tidak sadar. Konflik terjadi ketika individu harus memilih antara yang tidak sesuai, target atau perilaku (Wintoro 2018) . Penelitian sebelumnya menyebutkan bahwa pada dokter, stres dapat terjadi karena situasi yang tidak terkontrol, tidak terprediksi, dan perubahan besar yang terjadi. Ketika permasalahan tidak kunjung selesai, dapat menyebabkan stres jangka panjang dan mengakibatkan individu terbiasa dengan stres, kehilangan harapan, dan menyerah mencari solusi (Olpin and Hesson 2013). Kombinasi dari beberapa stres di pekerjaan, karakteristik individu dan hal-hal di luar pekerjaan disebut dengan istilah occupational stress. Terdapat beberapa sumber yang dapat menyebabkan occupational stress. Beberapa sumber tersebut berhubungan dengan pekerjaannya, yaitu yang berhubungan dengan peran individu dalam pekerjaan tersebut, hubungan antar pegawai, dan struktur dan iklim dari organisasi tersebut. Karakter individu pun berhubungan dengan kondisi stres, yaitu karakteristik seperti tingkat kecemasan dan toleransi terhadap ketidakpastian. Sumber stres juga dapat berasal dari luar lingkungan pekerjaan, seperti masalah keluarga, krisis hidup, masalah ekonomi, dan faktor lingkungan lainnya (Greenberg 2011).

Berbagai model konseptual stres didiskusikan dan dikembangakan kepada dokter gigi. Berdasarkan latar belakang di atas maka penulis tertarik membahas "faktor - faktor yang menyebabkan stress pada dokter gigi".

Syafrudin Aulia Azhar ${ }^{1}$, Heru Sulistyo ${ }^{2}$ - Analysis Of Factors That Cause Stress In Dentists: Literature Review

[Vol 11, No 1 (2020): April 2020] JBTI 


\section{METODE PENELITIAN}

Metode yang digunakan dalam penulisan artikel ini adalah literature review. Yaitu sebuah pencarian literatur baik internasional maupun nasional. Pada tahap awal pencarian artikel jurnal diperoleh lebih dari 10 artikel dari 2004 sampai 2020 menggunakan kata kunci "stres pada dokter gigi", dan "stress kerja pada tenaga kesehatan". Penulis sangat kesulitan dalam menemukan artikel tentang stress pada dokter gigi, karena jumlahnya sangat sedikit. Artikel-artikel tersebut diidentifikasi yang belum dieksplorasi relevansi dengan artikel untuk dikompilasi. Dari jumlah tersebut hanya beberapa artikel yang dianggap relevan. Dari jumlah artikel karena tidak ada 10 artikel yang memiliki kriteria penuh, kurang dari beberapa artikel yang berkualitas menengah, dan dua artikel yang berkualitas rendah.

\section{HASIL DAN PEMBAHASAN}

Berdasarkan artikel sebelumnya faktor risiko yang diteliti dari demografi individu dokter gigi meliputi usia, jenis kelamin, status pernikahan, lama kerja, dan masa kerja. Selain itu tuntutan kerja, keadaan organisasi, kondisi lingkungan kerja dan dukungan social juga diteliti sebagai factor risiko. Pada penelitian sebelumnya terdapat 85 dokter gigi yang menjadi sampel dan dipilih secara acak. Tingkat stress responden di ukur menggunakan skala DASS 42 (Depression Anxiety Stres Scale 42) (Mutiah 2019).

Tabel 1. Distribusi frekuensi faktor risiko tuntutan kerja, keadaan organisasi, kondisi lingkungan kerja, dukungan sosial dan tingkat stres kerja pada dokter gigi (Mutiah 2019).

\begin{tabular}{|c|c|c|}
\hline Variabel & $\mathbf{N}$ & Persentase \\
\hline \multicolumn{3}{|l|}{ Tuntutan Kerja } \\
\hline Tidak Berisiko & 85 & $100 \%$ \\
\hline Berisiko & 0 & $0 \%$ \\
\hline \multicolumn{3}{|l|}{ Keadaan Organisasi } \\
\hline Tidak Berisiko & 85 & $100 \%$ \\
\hline Berisiko & 0 & $0 \%$ \\
\hline \multicolumn{3}{|l|}{ Kondisi Lingkungan } \\
\hline Tidak Berisiko & 56 & $100 \%$ \\
\hline Berisiko & 29 & $34,11 \%$ \\
\hline \multicolumn{3}{|l|}{ Dukungan Sosial } \\
\hline Tidak Berisiko & 85 & $100 \%$ \\
\hline Berisiko & 0 & $0 \%$ \\
\hline \multicolumn{3}{|l|}{ Stres Kerja } \\
\hline Tidak Berisiko & 82 & $96,4 \%$ \\
\hline Berisiko & 3 & $3,6 \%$ \\
\hline
\end{tabular}

Kondisi lingkungan menjadi variabel utama yang berpengaruh pada stress dan memiliki nilai sebanyak 34,11\% sehingga berisiko sebagai pemicu stress (Mutiah 2019).

Studi lain memunculkan fakta bahwa terdapat kondisi stres yang tinggi pada dokter gigi. Penyebabnya adalah konflik dengan rekan kerja. Mayoritas dokter gigi berpendapat bahwa menerima kritik tentang pekerjaan adalah faktor pemicu stres. Dalam penelitian tersebut, konflik menjadi penyebab utama dan di antara semua pemicu stres yang diteliti hasilnya adalah 19\%. Hal tersebut bahkan menjadi niat turnover dari dokter gigi (Abdullah 2013). 
Tabel 2. Correlation matrix of all variables $(\mathrm{n}=100)$

\begin{tabular}{|lcccc|}
\hline Variables & I & II & III & \\
\hline Role Overload & --- & & & \\
Role Conflict & $.34^{* *}$ & $.58^{* *}$ & $\ldots$ & \\
Turnover Intention & $.26^{* *}$ & $.35^{* *}$ & $.39^{* *}$ & $\ldots$ \\
\hline
\end{tabular}

Tabel 3. Regression for role stressors with turnover intention $(n=100)($ Abdullah 2013)

\begin{tabular}{|lcccc|}
\hline & B & SE & $\beta$ & t \\
\hline Constant & 3.60 & 1.99 & - & $1.80^{*}$ \\
Role overload & .09 & .07 & .14 & 1.36 \\
Role conflict & .22 & .09 & .26 & $2.34^{*}$ \\
$\mathrm{R}^{2}=.19$ & & & & \\
$\Delta \mathrm{R}^{2}=.16$ & & & & \\
$\mathrm{~F}=05.85$, df $4,95, \mathrm{p}<.001$ & & & & \\
${ }^{*} \mathrm{p}<.01$ & & & & \\
\hline
\end{tabular}

Penelitian lain bahkan meneliti tingkat stress pada dokter gigi berdasarkan 3 klasifikasi, yaitu 38,8\% mengalami stres berat, $41,1 \%$ stress sedang, dan 20,2\% tidak mengalami stres. Hasil lain terdapat 61 dokter gigi atau sekitar 18,6\% menunjukkan kelelahan emosional sedang atau tinggi. Berdasarkan table di bawah, Rata-rata skor PSS dokter gigi dalam penelitian tersebut dilaporkan lebih tinggi dari kisaran rata-rata PSS (17,8 + 6,2) (Azad 2013).

Tabel 4. Perceived Stress Scale results (Azad 2013)

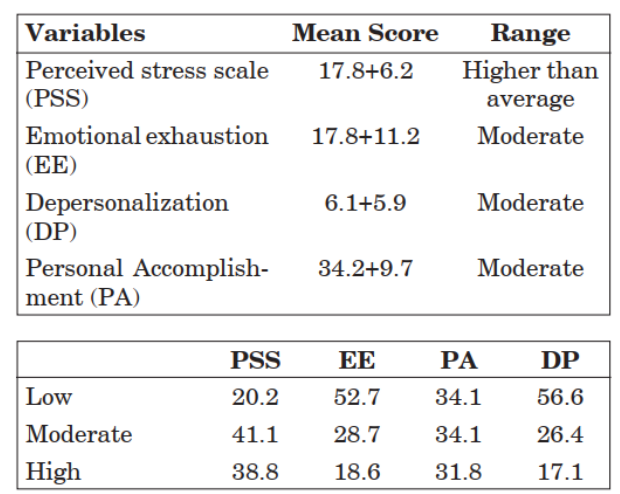

\section{Pembahasan}

Pada tahun 2015, masyarakat Amerika Serikat yang mengalami stres mencapai angka 77\% dan paling banyak diakibatkan oleh stres kerja. Diperkirakan terjadi kerugian lebih dari 300 milyar US Dollar tiap tahunnya akibat stres kerja. Sedangkan di Inggris pada tahun yang 2014/2015, prevalensi stres kerja, depresi dan ansietas sebesar 440.000 kasus. Umumnya stres kerja ini dapat disebabkan faktor sosial, faktor individu dan faktor diluar organisasi. Faktor sosial merupakan faktor yang paling mudah untuk diidentifikasi dan intervensi. Faktor sosial salah satunya adalah beban kerja berlebih. Hal ini menyebabkan tidak tercapainya target atau ekspektasi yang diemban. Selain itu, masalah konflik peran dan tanggung jawab terhadap orang lain berpengaruh pada stres kerja. Stres kerja mempunyai hubungan bermakna dengan gejala gangguan mental emosional melalui stresor tanggung jawab terhadap orang lain. Ketaksaan atau ambiguitas dalam penugasan juga akan menjadikan sumber ketegangan dan stres kerja yang tinggi (Tantra 2015).

Pada dasarnya setiap individu pasti mengalami kondisi stress. Jelas bahwa stres yang berlebihan bisa membahayakan setiap orang (Gaol 2016). Saat seseorang mengalami stres, sistem saraf otonom akan terpicu, yang menyebabkan supresi dari sistem saraf parasimpatis dan aktivasi

Syafrudin Aulia Azhar ${ }^{1}$, Heru Sulistyo ${ }^{2}$ - Analysis Of Factors That Cause Stress In Dentists: Literature Review [Vol 11, No 1 (2020): April 2020] JBTI 
dari sistem saraf simpatis. Hal tersebut akan meningkatkan sekresi dari hormon epinefrin dan norepinefrin ke dalam peredaran darah, yang menyebabkan berbagai efek dalam tubuh, seperti vasokonstriksi pembuluh darah, peningkatan tekanan darah, peningkatan kontraltilitas otot, pelepasan hormon stres, dan peningkatan denyut jantung (Adareth and Purwoko 2017).

Stres dapat memiliki efek yang merugikan pada dokter gigi dan diketahui berhubungan dengan tekanan fisik, tekanan psikologis, kelelahan emosional dan kelelahan. Studi tersebut memunculkan fakta bahwa ada tingkat stres mental dan fisik yang tinggi pada dokter gigi (Abdullah 2013). Penelitian sebelumnya Faktor risiko yang diteliti adalah demografi individu meliputi usia, jenis kelamin, status pernikahan, lama kerja, masa kerja, tindakan yang sering dilakukan dan status kepegawaiaan. Faktor tuntutan kerja, keadaan organisasi, kondisi lingkungan kerja dan dukungan social juga diteliti. Dari hasil penelitian tersebut dapat dilihat bahwa factor kondisi lingkungan yang memiliki peran sebagai factor stress. Oleh sebab itu dilakukan penjabaran masing-masing item pertanyaan dalam sebuah angket angket (Mutiah 2019).

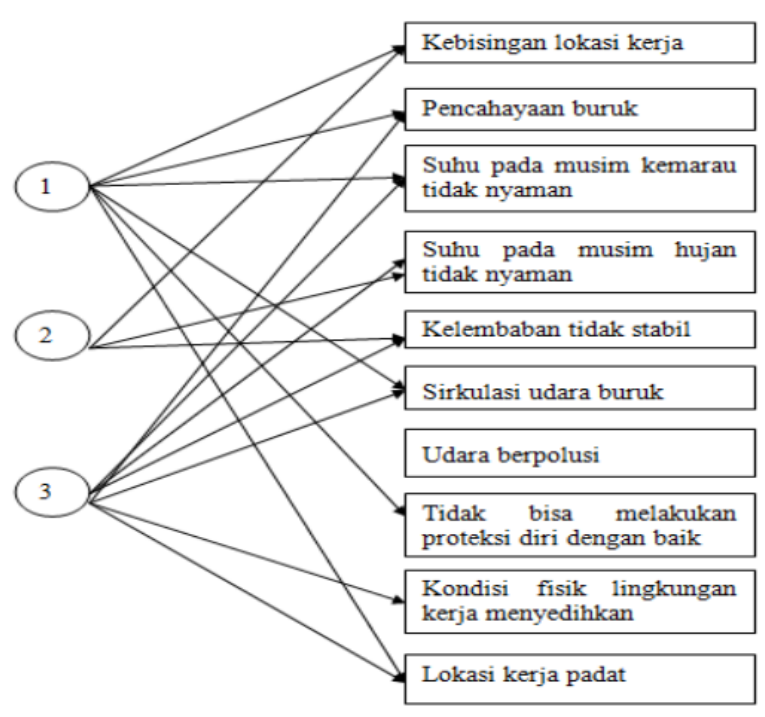

Gambar 1. Contoh skema gambaran responden yang berisiko stres kerja terkait item pernyataan pada variabel kondisi lingkungan kerja (Mutiah 2019).

Pada Gambar 1. dapat dilihat bahwa ketiga responden menyatakan bahwa mereka tidak nyaman dengan keadaan lingkungan kerja mereka yang berantakan dan suhu yang terlalu panas. Hal tersebut mengakibatkan dokter gigi merasa tidak nyaman saat berkerja. Selain itu kebisingan juga dianggap dapat mengganggu konsetrasi mereka dalam berkerja karena menurut responden hal tersebut dapat mengganggu konsentrasi kerja (Mutiah 2019). Kondisi lingkungan kerja yang buruk sering menjadi pencetus stres di tempat kerja. Dimulai dari ruangan yang tidak memadai untuk beroperasi dengan nyaman, control suhu dan kelembaban yang tidak baik juga dapat menimbulkan ketidaknyamanan. Tingkat kebisingan yang berlebihan juga bias memecah konsentrasi. Ventilasi yang tidak adekuat, mengakibatkan ketidaknyamanan, terutama di saat musim panas (Stranks 2005). Ruang Praktik adalah tempat berkerja utama bagi dokter gigi. Tata letak ruang praktik perlu diperhatikan, dimana peralatan dalam ruangan ini berorientasi memberi kemudahan dan kenyamanan bagi dokter gigi, perawat gigi, berserta pasiennya ketika proses perawatan dilakukan. Ukuran minimal ruang perawatan untuk satu Dental Unit adalah 2,5 X 3,5 meter, dalam ruangan ini dapat dimasukan satu buah Dental Unit, Mobile Cabinet, serta dua buah Dental Stool (Endro 2004).

Syafrudin Aulia Azhar ${ }^{1}$, Heru Sulistyo ${ }^{2}$ - Analysis Of Factors That Cause Stress In Dentists: Literature Review [Vol 11, No 1 (2020): April 2020] JBTI 
Dalam penelitian lain, konflik antar rekan kerja ditemukan menjadi penyebab utama di antara semua stres yang diteliti dan berkontribusi $19 \%$ dari niat turnover dari dokter gigi. Konflik menjadi situasi yang sangat mengkhawatirkan karena bertanggung jawab atas banyaknya tekanan pada dokter gigi. Para dokter gigi yang terus menerus menghadapi konflik mencapai fase kelelahan atau kelelahan. Sementara itu konflik dapat dengan mudah diselesaikan atau dapat dihindari dengan bantuan partisipasi aktif dan tulus dari administrasi atau kepala unit di tempat kerja. Dokter gigi kami tidak menyadari terlalu banyak pengaruh konflik pada lingkungan kerja mereka (Abdullah 2013).

Sebuah penelitian terhadap lebih dari 3.500 dokter gigi menemukan bahwa 38 persen dari mereka yang disurvei sering mengalami khawatir atau cemas. Selain itu, 34 persen responden mengatakan bahwa mereka selalu atau sering merasa lelah secara fisik atau emosional, dan 26 persen mengatakan mereka selalu atau sering mengalami sakit kepala atau sakit punggung. Gejalagejala ini sering dikaitkan dengan kegelisahan dan depresi (Rada and Johnson-Leong 2011). Dalam penelitian tersebut dikonfirmasi bahwa dokter gigi mengalami banyak tekanan dalam lingkungan kerja (Abdullah 2013).

\section{KESIMPULAN DAN SARAN}

Dokter gigi merupakan salah satu tenaga kesehatan yang sangat penting bagi sejahteranya kesehatan masyarakat. Sebagai tenaga yang dituntut berkerja secara professional, tentunya dokter gigi bisa mengalami stres. Stres dapat menjadi stimulus untuk bekerja lebih baik apabila dalam taraf fisiologis, bila stres dalam kadar berlebih maka akan mengakibatkan gangguan fisik dan psikologi yang pada akhirnya menurunkan kinerja dan dapat mengganggu pelayanan kesehatan. Dokter gigi sering tidak menyadari kondisi mereka mengalami stress. Berdasarkan penelitian penelitian yang ada faktor-faktor yang mengakibatkan dokter gigi menjadi stress adalah keadaan lingkungan kerja dan konflik antar rekan kerja. Dokter gigi yang mengalami stress biasanya akan sering merasa lelah secara fisik atau emosional dan mengalami sakit kepala atau sakit punggung. Evaluasi dan perbaikan terkait kinerja dokter gigi perlu dilakukan oleh dinas kesehatan, organisasi resmi dokter gigi, dan institusi tempat berkerja sebagai langkah preventif agar angka kejadian stress kerja pada dokter gigi tidak meningkat.

Artikel ini mempunyai banyak kekurangan sehingga perlu dilakukan penelitian lebih lanjut dengan sampel dokter gigi di masing-masing daerah di Indonesia. Keterbatasan artikel ini adalah pengambilan data dan sumber yang bias dibilah sedikit, sehingga penulis tidak bisa memastikan apakah dokter gigi benar-benar mengalami stress dengan factor-faktor yang telah disebutkan. Perlu dilakukan penelitian lebih lanjut untuk mengidentifikasi stress pada dokter gigi sehingga bias mencari jalan keluar dan solusi agar meminimalisir stress pada dokter gigi.

\section{DAFTAR PUSTAKA}

Abdullah, Saeeda. "Comparison Of Role Stressors, Job Satisfaction And." Pakistan Oral \& Dental Journal Vol 33, No. 3, 2013.

Adareth, Therisa, and Yosef Purwoko. "Musik Klasik Menurunkan Tingkat Stres Mahasiswa." Jurnal Kedokteran Diponegoro Vol. 6, No.2, 2017.

Azad, Azad Ali. "Prevalence Of Stress And Burnout Among Dentists Of Rawalpindi \& Islamabad." Pakistan Oral \& Dental Journal Vol 33, No. 3, 2013.

Brun, Jean-Pierre. "Stress at The Workplace." World Health Organization. 8 March 2020. https://www.who.int/occupational_health/topics/stressatwp/en/.

Endro, H. "Prespektif Baru Dalam Desain Tempat Praktek." Dentamedia Nomor 1 Vol.8 , 2004.

Fajrillah. "Hubungan Stres Kerja Dengan Kinerja Perawat Pelaksana Dalam Melaksanakan Pelayanan Keperawatan Di Instalasi Gawat Darurat Rumah Sakit Umum Anutapura Palu." Jurnal Keperawatan Sriwijaya, Volume 3 - Nomor 2, 2016.

Syafrudin Aulia Azhar ${ }^{1}$, Heru Sulistyo ${ }^{2}$ - Analysis Of Factors That Cause Stress In Dentists: Literature Review

[Vol 11, No 1 (2020): April 2020] JBTI 
Gaol, Nasib Tua Lumban. "Teori Stres: Stimulus, Respons, dan Transaksional ." Buletin Psikologi Vol. 24, No. 1, 2016: 1-11.

Greenberg, J. Comprehensive Stress Management. New York: McGraw-Hill, 2011.

Kemenkes. "Pokok-Pokok Renstra Kemenkes 2020-2024." Rapat Kerja Kesehatan Nasional . Jakarta: Kementerian Kesehatan Replubik Indonesia, 2020.

Leka, Stavroula, Amanda Griffiths, and Tom Cox. WORK ORGANIZATION \& STRESS. Nottingham: WHO, 2004.

Mutiah, Chelly. "Analisis Faktor Risiko Terjadinya Stres Kerja pada Dokter Gigi di Kota Palembang." SRIWIJAYA JOURNAL OF MEDICINE Volume 2 No.1, 2019: Hal 46-51.

Olpin, M., and M Hesson. Stress Mangement for Life: A Research-Based, Experiential Approach. Belmont, CA: Wadswroth, Cengage Learning, 2013.

Rada, Robert E., and Charmaine Johnson-Leong. "Stress, burnout, anxiety and depression among dentists." JADA, 2011: 135:788-94.

Sholekhah, Nur Khamilatusy. "Peningkatan Kinerja SDM Perawat Berbasis Rotasi Kerja." Fakultas Ekonomi Universitas Islam Sultan Agung, 2017.

Stranks, J. Stress at Work Management and Prevention. Elsivier, 2005.

Tantra, M. Sultan. "Faktor-Faktor Sosial yang Mempengaruhi Stres Kerja." Majority, Volume 4, No.9, 2015: 58-63.

Willda, Tesa. "Hubungan Resiliensi Diri Terhadap Tingkat Stres Pada Dokter Muda Fakultas Kedokteran Universitas Riau." Jom FK Volume 3 No. 1, 2016.

Wintoro, Annisa Yuliarahma. "Mengenal Lebih Dekat: Stress Kerja Pada Dokter Internsip." Journal of Psychological Science and Profesion (JPSP) Vol.2, No.1., 2018.

Wiramihardja, 12. S. A. Pengantar Psikologi Klinis. Bandung: Refika Aditama, 2015.

Wirawan. Menghadapi Stres dan Depresi: Seni Menikmati Hidup Agar Selalu Bahagia. Platinum, 2012.

Syafrudin Aulia Azhar ${ }^{1}$, Heru Sulistyo ${ }^{2}$ - Analysis Of Factors That Cause Stress In Dentists: Literature Review

[Vol 11, No 1 (2020): April 2020] JBTI 